\title{
Simón Bolívar, sua Posição na História e na Atualidade ${ }^{1}$
}

Max Zeuske

A Seção de Ciências Latino-Americanas sente-se altamente honrada por ter a oportunidade de realizar um colóquio sobre o Libertador Simón Bolívar, sobre a avaliação de sua atuação e sua posição durante e na Revolução de Independência. A nosso juízo, a meta do colóquio deveria ser a de elaborar e chegar a certa unificação dos critérios marxistas-leninistas sobre a figura do Libertador, tanto como indivíduo como enquanto sua representação ou personificação da revolução de independência naquela parte da América na qual ele atuou.

Levando em conta que a figura de Bolívar não está morta, senão que vive na consciência dos povos latino-americanos, e que se converteu na personificação do mais progressista e revolucionário dentro do acervo das tradições históricas positivistas, realçamos a imensa importância que tem a correta e multifacetada interpretação de Bolívar e de sua obra para nosso trabalho em comum nos terrenos da ciência e dos combates ideológicos. Por isto devemos entender nosso debate como uma contribuição direta à luta que levam todas as forças progressistas, democráticas e revolucionárias da América Latina contra a dominação imperialista, os regimes retrógrados e fascistas, para avançar em direção a um futuro melhor dos povos latinoamericanos, vendo-o dentro da perspectiva universal do mundo atual, no qual a luta se dá cada vez mais pronunciadamente entre a ruína total e comum da humanidade e a destruição definitiva do imperialismo como condição imprescindível para qualquer progresso ulterior. Se então Bolívar queria, mediante a independência e a união dos Estados libertos, estabelecer uma nova "balança do universo", o que nem objetivamente nem subjetivamente poderia se conquistar, na atualidade a participação mais ativa da América Latina no estabelecimento de tal "balança do

\footnotetext{
${ }^{1}$ Agradecemos a Michael Zeuske, também historiador e atualmente professor e pesquisador do Departamento de História da América Latina e Ibérica na Universidade de Colônia-Alemanha, quem gentilmente nos autorizou a tradução e publicação do artigo. Tradução do original em castelhano por Elizabeth del Socorro Ruano Ibarra e Raphael Lana Seabra.

${ }^{2}$ Nascido em Berlim em 1927 e falecido em Oranienburg em 2001, Max Zeuske foi um historiador alemão, foi professor entre 1951-1993 passando pela Universidade de Leipzig, professor visitante na Universidade de Havana e encerrando sua carreira na Universidade de Rostock, cuja pesquisa voltava-se para História da América Latina, tendo pesquisado sobre a Revolução Cubana, Simón Bolívar e Agusto César Sandino.
} 
universo" é não apenas uma necessidade histórica, mas também possível. Esta ideia de Bolívar, antecipadora do papel universal ativo de sua América, está se convertendo cada vez mais numa necessidade objetiva e em realidade de acordo e a medida em que avança o processo revolucionário atual.

Nesta exposição não quero fazer uma biografia completa do Libertador e nem quero nem posso me referir à totalidade dos aspectos necessários a tal consideração, tendo em conta, portanto, que vocês em seus aportes vão se ocupar de alguns muito importantes ${ }^{3}$. Assim, aspiro expor aqui apenas uma base para a discussão.

Desde a fase de gestação da revolução, ou seja, desde 1808, e nos sucessos insuficientemente pesquisados, Bolívar se apresenta entre os elementos ativos como um dos mantuanos ${ }^{4}$ conjurados para estabelecer a Junta Suprema Governativa (NUCETE-SARDI, 1969). Ainda que esta conjuração não tenha resultado em nada, é muito significativo que Bolívar já tenha pertencido aos que reagiram ativamente frente à crise da metrópole e às cambiantes circunstâncias internacionais. Este traço bolivariano se apresenta mais marcadamente durante os eventos de 1810 e 1811 . Pode ser que sua nomeação como chefe da delegação enviada para Londres deva-se a relações derivadas de seu alto estrato social entre os membros da Junta ou a outra causa exterior; o que chama a atenção em sua atuação prática é o fato de que ele se sinta autorizado, ainda que na verdade fosse bem ao contrário, para demover Miranda a viajar para a Venezuela; não sabemos se isto foi por iniciativa própria ou por encargo de um grupo de patriotas por trás dele. Portanto, o notável é que sua própria iniciativa desencadeia consequências bem previsíveis na densa atmosfera desse ano. Não me refiro extensamente aqui ao próprio Miranda, mas me ocorre propor certa equiparação com o que Marx disse sobre Espartero ${ }^{5}$; em certo sentido Miranda era, em 1810, o que Marx disse em 1854 de Espartero: era uma das “personificações individuais

\footnotetext{
${ }^{3} \mathrm{O}$ autor refere-se aos outros trabalhos que foram apresentados no Colóquio, um deles segue publicado no presente número, de autoria de Manfrek Kossok (Nota das tradutoras).

${ }^{4}$ Essa adjetivação surgida inicialmente em Caracas e, posteriormente, difundida pela Venezuela, é relativa ao branco criollo ligado à aristocracia local. A princípio referia-se aos enormes mantos que a mulheres, sobretudo, brancas vestiam para acompanhar as missas ou festividades religiosas no século XVI (N.T.).

${ }^{5}$ Segundo o dicionário político,Espartero Baldomero Fernández (1793-1879) foi um general e estadista espanhol, regente de Espanha (1841-1843), chefe do governo (1854-1856) e dirigente do partido dos progressistas (N.T.).
} 
da revolução", as que não são "nenhum ser real, sendo um fantasma, um nome, uma reminiscência" (MARX, 1961b, p.385). Escondido atrás de Miranda está todo o grupo de ativos elementos ao qual pertencem Bolívar, os Ribas e todos os quais, talvez sem muito fundamento, foram chamados de grupo bolivariano, o que mais parece refletir uma justificativa retrospectiva. Mas seja como for, novamente Bolívar está entre os mais ativos, os que mantêm a iniciativa própria e independente, entre os que estão empurrando e acelerando o processo. Tudo isto parece que ainda não tem maiores e nem menores conotações de uma revolução social. Mas ao nível político Bolívar já está em sua ala esquerda desde o início do processo que se converte em processo revolucionário. Se fosse lícito aplicar aqui o critério leninista de diferenciação entre nacional-reformista e nacional-revolucionário, Bolívar já estaria entre estes. Ou para utilizar de novo um critério de Marx, parafraseando: "Não esperava que chegasse a revolução, a buscava" (MARX, 1961, p. 385). Parece-me muito importante sublinhar isso, porque esta atitude bolivariana implica em muito do que ele revelará bem mais tarde, depois das amargas experiências da primeira fase da revolução entre 1810 e 1815.

Se ideologicamente for característico um liberalismo revolucionário para Bolívar, desde os períodos iniciais ele sempre esteve muito mais próximo a um revolucionarismo pragmático que a um liberalismo dogmático. Isto não parece uma interpretação a fortiori, mas reflete sua atuação prática nos fatos positivos, como durante os eventos em Caracas que conduziram à Declaração de Independência e ao estabelecimento da Primeira República em 1811. Bem conhecido é seu discurso de 4 de julho de 1811, pujante dentro de uma estratégia extra-parlamentar: "Que os grandes projetos devam se preparar com calma! Trezentos anos de calma não bastam? A Junta Patriótica respeita, como deve, o Congresso da nação, mas o Congresso deve escutar a Junta Patriótica, centro de luzes e de todos os interesses revolucionários. Coloquemos sem temor a pedra fundamental da liberdade sul-americana: vacilar é nos perder" (BOLIVAR, 1982b, p. 535). De fato, este movimento empurrado por Bolívar obrigou o Congresso a declarar a independência no dia seguinte.

Com este movimento Bolívar levou a seu êxito final os abortados movimentos de massas dos anos 1810, conduzidos pelos irmãos Ribas (MAGALLANES, 1975, p. 158). Claro que as relações entre Bolívar e as massas urbanas inferiores, determinadas meramente por motivos políticos, podem ser interpretadas como relações de caráter 
demagógico. No entanto, não me parece ser assim pelas atitudes positivamente nãodemagógicas de Bolívar em tempos posteriores.

\section{II}

Em relação a atitude bolivariana durante a primeira fase da revolução, entre 1810 e 1815, combinam-se duas características bem marcadas. A primeira, consequência direta de sua atitude em julho de 1811, é sua decisão precoce e firme para uma independência plena e a instauração da plena soberania nacional. Também a respeito desta firme decisão, Bolívar encontra-se na ala esquerda entre os criollos. Certamente, a relativamente rápida decisão de Caracas foi acelerada ainda mais pela situação competitiva na qual se encontrou Caracas frente a outros centros da colônia formada só 34 anos antes.

Por outra parte, Bolívar não se diferencia ainda dos demais líderes criollos quanto à condução da guerra, baseada unicamente nas cidades. Com muita razão, Manfred Kossok indicou que esta primeira fase da revolução foi uma mera revolução urbana e isso, claramente, nos parece expressão do outro aspecto que faltava a revolução: um aprofundamento social; porque a s principais questões sociais do país se ligavam com o meio rural e as relações urbano-rurais. Por isso também, esta primeira fase assume muitos aspectos de uma guerra entre a cidade e o campo, sendo o campo o principal baluarte social da contrarrevolução. Sob este aspecto, durante esta primeira fase Bolívar se encontra na ala social-conservadora.

Mas com esta repartição de um homem não se penetra o suficiente na personalidade de Bolívar. Existe entre sua radicalidade política e seu conservadorismo uma relação contraditória, e creio que esta ligação está formada pela questão do poder. Já que a questão do poder é e foi a questão principal da revolução, a atitude de cada um frente a ela deve ser medida na exata medida. E creio que em Bolívar esta questão principal se manifesta, fundamentalmente, através de sua atitude frente ao dilema entre federalismo e centralismo, porque, como veremos e como é bem conhecido, era Bolívar - junto ao neogranadino Antonio Nariño - o principal defensor do centralismo. Na maioria das vezes o centralismo bolivariano encontra-se interpretado como expressão de sua tendência ditatorial, distorcendo e falsificando a lógica de seu procedimento. Não estamos, portanto, discutindo a questão da ditadura, deixando-a 
para mais tarde. Proponho que nós devemos ver a questão do federalismo ou centralismo ao contrário.

Socioeconomicamente, o federalismo criollo é a expressão constitucional e política da mera existência regional e local da aristocracia latifundiária e escravista, ou seja, expressão da falta de coesão socioeconómica nacional. O centralismo, por outra parte, ou melhor, pelo contrário, é a expressão política de uma meta socioeconômica progressista e um dos meios principais para alcançá-la. Isto está claro dentro de uma perspectiva de longo alcance. Para uma perspectiva de menor alcance, o centralismo é o único meio de triunfar numa luta de morte. Mas em qualquer aspecto a formação centralista reflete uma concepção de desenvolvimento político e nacional principalmente diferente, uma visão também diferente dos interesses de classe da aristocracia latifundiária, no terreno da relação dialética entre Estado e nação. O centralismo bolivariano aparece assim como a alavanca principal para criar "desde cima”, para assim dizê-lo, a nação. Vendo desta maneira, nos revela a ligação lógica entre a atitude de Bolívar durante a primeira fase da revolução e a segunda fase a partir de 1815/1817, quer dizer, propugnando já durante a primeira fase o centralismo militar e político-constitucional, já tendo em conta mais ou menos confusamente suas implicações ulteriores, ele cimentou o caminho para posições superiores durante a segunda fase.

São bem conhecidos os juízos de Bolívar sobre o federalismo durante a primeira fase e basta citar alguns poucos parágrafos. Já em sua "Memória dirigida aos cidadãos de Nova Granada", o Manifesto de Cartagena de dezembro de 1812 diz: "o que mais debilitou ao governo da Venezuela, foi a forma federal adotada, seguindo as máximas exageradas dos direitos do homem, que autorizando-o para que se reja por si mesmo, rompe os pactos sociais (itálico de M. Z.), e constitui as nações em anarquia... Eu sou do sentimento que enquanto não centralizarmos nossos governos americanos, os inimigos obterão as mais completas vantagens; seremos indefectivelmente envolvidos nos horrores das dissensões civis e conquistados vilipendiosamente por esse punhado de bandidos que infestam nossas comarcas" (BOLÍVAR, 1929, p.39).

E exatamente dois anos mais tarde, a partir de Santafé: "estou determinado a tomar Santa Maria, Maracaibo, Coro e voltar por Cúcuta, a libertar o sul até Lima, se é possível; mas para isto é necessário que tudo marche uniformemente e que não se faça 
nada fora do plano que me propus, pois na unidade consiste a melhor parte de nossos bons sucessos" (BOLÍVAR, 1929, p.113).

O que se pode deduzir das atitudes bolivarianas descritas? Tendo objetivamente posições sociais-conservadoras durante a primeira fase na relação dialética entre o nível político e o nível social, Bolívar por suas posições políticas já durante esta primeira fase elabora os pontos de partida para chegar a uma compreensão e a uma estratégia superiores da luta pela nação, possuindo já nesta fase uma ideia muito mais clara que outros líderes sobre o Estado nacional. Não deve nos irritar o fato de que há certa hipertrofia do aspecto político, a qual se reflete, por exemplo, na "Guerra de morte"; ela deve-se ao prevalecimento objetivamente necessário dos meios políticos sobre as medidas sociais, causada entre outros fatores também pela carência de um agrupamento coerente de líderes com uma visão realmente nacional tal qual a do próprio Bolívar. Nota-se neste ponto que nos falta ainda um estudo sobre a formação do "grupo bolivariano", sua composição e suas contradições internas; estudo necessário para compreender melhor as limitações sociais do próprio Bolívar durante este período, como nos explicar seus avanços da compreensão do processo revolucionário materializados na Carta de Jamaica e claramente visíveis nela. Porque, segundo nossa concepção, o gênio revolucionário de Bolívar e seu reconhecimento inclui a busca das relações dentro deste processo epistemológico social, entre indivíduo e, se é permitida a utilização do termo, o "coletivo" ideologicamente próximo a ele. Ou seja, em que medida outras personalidades contribuíram à reformulação da estratégia e tática revolucionárias ao se passar da primeira à segunda fase da revolução?

\section{III}

A segunda fase, a qual estabelecemos entre 1815 e 1821, é a própria fase "bolivariana" no teatro setentrional da guerra de independência. Como citado no Manifesto de Cartagena, também na Carta de Jamaica concretizou-se a capacidade de Bolívar nas aras do seguimento ulterior da revolução, de aprender com seus erros e debilidades, de fazer a si mesmo e a sua classe uma profunda autocrítica. De forma ainda muito mais visível que durante a primeira fase demonstra-se sua inclinação não para um liberalismo dogmático, mas para o realismo revolucionário. Todavia, não se 
deve - com toda a importância que tem - superestimar Bolívar e sua Carta. Por uma parte, enquanto concepção estratégica aprofundada por sua classe na revolução, marca de fato uma virada. Mas essa relativa mudança de rumo não é, de imediato, nada mais que uma virada teórica. A outra face da moeda está conformada pelo fato, até agora não sistematicamente pesquisado, da luta de grupos guerrilheiros patrióticos no interior, e de que estes grupos começavam a se inclinar mais e mais para o lado dos patriotas. O pesquisado a esse respeito, especialmente por Miguel Acosta Saignes (1977), confere aos Llanos Orientais ${ }^{6}$ um bom testemunho disto. Menciona nomes de líderes que haviam lutado nos llanos durante dois anos, entre 1814 e 1816, como Monagas, Zarara, Rojas, Barreto, Sedeño, ressaltando a reunião destes líderes para se unir e coordenar lutas, em San Diego de Cabrutica, em maio de 1816 (ACOSTA SAIGNES, 1977, p.204). Em resumo diz: “a maior parte dos chefes militares eram de origem humilde e analfabeta" (Idem, p. 207).

"De 1815 a 1817, sobressaiu extraordinariamente a atitude de cooperação, assim como o papel do povo, da gente comum inclusive os escravos, na luta anticolonialista. O restante do exército organizado por Mariño em 1813, os escravos libertos por Bideau antes de abandonar a Güria, as guerrilhas encabeçadas por Sedeño, Zaraza, Monagas, Rojas, Barreto e outros menos conhecidos, como Sarmiento, os quais eram disputados pelos espanhóis como um dos mais capazes dirigentes, os llaneros de Casanare e de Apure, encabeçados por Páez, as lutas das massas margaritenhas dirigidas por Gómez e Arismendi, realizaram durante 1815 e 1816 extraordinários esforços coletivos, mantiveram o ideal de independência vivo e combatente, demonstraram que a empresa já não era apenas desígnio dos mantuanos, mas sim de grupos de camponeses, de llaneros, de pescadores, de gente marginalizada, habitantes de montanhas e llanos, de picos e rochedos, decididos a criar uma sociedade distinta, até onde alcançasse suas forças" (ACOSTA SAIGNES, 1977, p.211).

\section{E com muita razão Acosta Saignes resume:}

"Até agora a maior parte daqueles que escreveram as histórias da Venezuela ou estudos sobre ela, não explicaram as causas pelas quais depois das grandes derrotas de 1814, a luta continuou. Atribuem apenas uma espécie de ação mágica dos

\footnotetext{
${ }^{6}$ São regiões de planície que cobrem a parte central da Venezuela e se estendem até a parte oriental da atual Colômbia. São marcadas por longos regimes de alternância entre chuvas e secas. Naquele período tinha por principal atividade econômica a criação de gado. De modo que os llaneros eram similares aos vaqueros mexicanos, gaúchos argentinos e vaqueiros do sertão brasileiro (N.T.).
} 
Libertadores no restabelecimento dos combates. Estes se fizeram sobre a base do movimento popular que resistiu por todas as partes e, além disso, pela continuidade da rebeldia em zonas esquecidas por aqueles que confundem a história do centro da República com a de todo país. o gênio sociológico, político e militar de Bolívar distinguiu com clareza as possibilidades mantidas por grandes conjuntos de combatentes em diversas regiões e soube numa grande luta pela unidade de propósitos e esforços, fazer cumprir os planos que traçou em vistas das circunstâncias" (ACOSTA SAIGNES, 1977, p.214-215).

Em nosso juízo, a Carta da Jamaica, que por sua vez resume a primeira e introduz a segunda fase da revolução no teatro de ações de Bolívar, deveria se situar numa dupla perspectiva: primeiro, a perspectiva estratégica revolucionário-nacional, que versa sobre a fundação das nações latino-americanas, e, segundo, a que trata mais indireta do que diretamente - da fundação das bases para a primeira. Não é nossa intenção tratá-la aqui detalhadamente, mas devemos citar alguns parágrafos curtos para demonstrar que já na Jamaica Bolívar se aproximou do conceito de aprofundamento social da revolução. Primeiro ao chegar à conclusão de que o que mais faz falta para seguir com a guerra revolucionária é a união: “o que pode nos pôr em atitude de expulsar os espanhóis e fundar um governo livre: é, certamente, a união; mas esta união não nos virá por bênçãos divinas" - como no México, com o culto à Virgem de Guadalupe - "senão por efeitos sensíveis e esforços bem dirigidos" (BOLÍVAR, 1982 p.174), quer dizer, por medidas reais para alterar a vida social do povo trabalhador, por sua organização e sua direção na luta. Bolívar capta também os efeitos contraditórios da contrarrevolução, e se dá conta de como seus efeitos estão surtindo sobre as massas do povo: "Os sul-americanos já não temem senão a tirania. Seu espírito se elevou. As perseguições da Espanha lhes tem dado a força de que necessitavam" (BOLÍVAR, 1982, p.177). E para que não reste dúvida de que se refere ao povo trabalhador, diz: "voltemos o olhar sobre a Venezuela, e veremos que seus habitantes quase aniquilados, sem armas e oprimidos, se levantam com tanta força e violência que, depois de haverem se apropriado de todas as províncias interiores, já ameaçam atacar os portos e lançar seus inimigos ao mar, segundo as últimas notícias que temos recebido" (BOLÍVAR, 1982, p.178). E numa carta adicional sobre a questão das raças acrescenta: "por um evento bem singular se tem visto que os mesmos soldados libertos e escravos que tanto contribuíram, ainda que a força, ao triunfo dos 
realistas, se voltaram ao partido dos independentes, que não haviam oferecido a liberdade absoluta, como o fizeram as guerrilhas espanholas. Os atuais defensores da independência são os mesmos partidários de Boves, unidos com brancos criollos, que jamais abandonaram esta nobre causa” (BOLÍVAR, 1982, p.180 - itálico de M.Z.).

Acontece então que Bolívar deve ter conceituado a ideia de supressão da escravidão, e que sua ida ao Haiti, depois da queda de Cartagena, deve-se exatamente a esta ideia. Isto não diminui nem um pouco os méritos do presidente Petión de ter possibilitado materialmente duas vezes as expedições de Bolívar à costa de Tierra Firme, mas tira o casual e romântico de um líder revolucionário que apenas é convencido pelo fato de visitar um país de escravos libertos e renuncia o mais elementar para sua própria classe exploradora: a classe explorada. Por sua vez, tira o aspecto puramente comercial de trocar apoio material em armamentos pela promessa de libertar seus próprios escravos.

Os eventos de 1816 e princípios de 1817 nos permitem ver como Bolívar supera as ilusões que ainda lhe restavam a respeito dos efeitos de uma declaração de liberdade dos escravos e, paralelamente, de poder liberar diretamente Caracas. A elaboração da estratégia tanto militar como social forma, ao fim, todo um processo muito longo. Seus resultados essenciais são:

$1^{\circ}$ ) A decisão de abandonar a "revolução urbana" em favor da "revolução rural", como muito acertadamente disse M. Kossok;

$2^{\circ}$ ) A libertação dos escravos que na realidade já haviam combatido nas guerrilhas e sua inclusão no exército revolucionário;

$3^{\circ}$ ) A decisão por um sistema de repartição de terras como pagamento de ativos militares, quer dizer, por serviços prestados;

$4^{\circ}$ ) A conversão de Guayana na base de sustentação e a guerra, do comércio e da institucionalização, e

5) A conceituação da marcha sobre os Andes para Nova Granada, o que fez possível o triunfo de Boyacá (1819) e depois o de Carabobo (1821).

Até agora não se estimou o suficiente a importância das medidas socioeconômicas de Bolívar. Ainda que a "ruralização" da luta revolucionária não seja precisamente um dos méritos que possam se atribuir unicamente ao gênio de Bolívar, foi ele quem lhe deu uma base socioeconômica através da liberação dos escravos e da 
atribuição de terras nacionais como recompensa por serviços militares. No entanto, devem ser formuladas inúmeras reservas.

Primeiro, que a aplicação inicial da política de atribuição de terras nacionais deve-se, em 1816, ao exército llanero de Apure sob José Antonio Páez, e que a incorporação deste exército ao exército libertador se realizou sob a condição de que Bolívar ratificasse esta política. Salcedo Bastardo o sugere com muita razão (SALCEDO BASTARDO, 1972, p.162). O que fez Bolívar foi estender esta política "a todos os corpos combatentes" através de seus decretos entre setembro e outubro de 1817 (Idem, p.163). Mas, contrariando a avaliação de Salcedo Bastardo (Idem, p.165), estas medidas não podem ser qualificadas como "reforma agrária", porque na realidade nem buscavam a modificação da estrutura agrária e nem a realizaram, carecendo de determinações para a destruição da grande propriedade da terra. O que buscavam era prover terras aos soldados e oficiais para que as fizessem produzir, isto sim.

Segundo, esta intenção de legislação agrária bolivariana foi deturpada já no Congresso de Angostura em 1820 (ACTAS, 1969, p.383), em duplo sentido: primeiro por incluir no direito de obter atribuição não só a militares, mas também aos empregados civis, e segundo, por substituir a entrega direta de terras por vales, com discriminação entre soldados e oficiais: “Art. 10ํ- O pagamento destas atribuições se fará pelo total à tropa e pelas metades à Oficialidade, em vales do Tesouro Público, que serão admitidos por seu valor nominal na subasta de bens nacionais". Não só o Congresso precisou de quase um ano para preparar esta lei, mas também que a deturpação acarretou que os vales foram vendidos por cinco por cento de seu valor a especuladores. Desta maneira o negócio dos vales se converteu dentro de poucos meses em meio eficaz de uma gigantesca concentração de terras repartidas sob esta definição de "repartição de bens nacionais". Além disso, mediante o Art. $7^{\mathfrak{0}}$ da mesma lei "pode o Presidente da República por ações muito distintas, com tal que as especifique, conceder recompensas extraordinárias em bens nacionais" (ACTAS, 1969, p.385), o que teve como resultado que dentre poucos anos a maior parte da alta oficialidade se converteu em grandes proprietários. A verdade é que Bolívar fora contrário da conversão das entregas em vales, mas não podia impor seus critérios. (SALCEDO BASTARDO, 1972, p. 170). Por consequência, surge neste terreno uma profunda contradição entre as intenções de Bolívar e as da maioria da oficialidade do exército libertador e, em especial, seus generais mais influentes (Idem, p.296). 
Terceiro: também a abolição da escravidão tinha seus antecedentes diretos na primeira fase da revolução, por um lado por vias de fato, que dizer, pela fuga massiva dos próprios escravos e sua adesão primeiro aos grupos que combatiam ao lado da contra revolução, e, depois, sua conversão para o lado patriótico, e, por outro lado, através de uma espécie de "legislação revolucionária”. Esta é referente à declaração de "liberdade geral dos escravos" pelo mulado Bideau em Güiria, na costa oriental em 185 (ACOSTA SAIGNES, 1977, p.174). Bolívar, chegando em 1816 a mesma região e se apoiando nos mesmos combatentes Mariño, Bermúdez e Bideau, se adapta a uma realidade revolucionária preexistente, proclamando a abolição da escravidão, primeiro condicionada e pouco mais tarde absoluta, então como Chefe Supremo da República, o que dá muito mais peso e extensão. Como no caso da repartição de bens nacionais, pede também a confirmação de seus decretos abolicionistas ao Congresso de Angostura.

Seria interessante investigar a questão se Bolívar, além de pensar na criação de um forte exército libertador para conduzir a guerra contra o domínio colonial, pode pensar no futuro pós-revolucionário, colocando com eles as bases de um regime variado socioeconomicamente em direção a um maior peso dos pequenos agricultores e trabalhadores agrícolas livres na estrutura agrária. Parece provável, ainda que por enquanto seja difícil responder afirmativamente todos os aspectos do problema.

Quarto: igualmente como no caso das posses nacionais, para a abolição urge ao Congresso a aprovar seus atos com os mais impressionantes argumentos. No entanto, a abolição tampouco será declarada, mas será praticamente restaurada a escravidão, mesmo que sob um manto abolicionista servil. Abolindo-se "de direito", "as coisas ficariam no mesmo modo em que se encontram hoje em dia", versa a lei de 11 de janeiro de 1820, e a decisão é proposta [no original está "pospuesta", mas creio ser erro de digitação] para ser vista no próximo Congresso (que ocorreu em Cúcuta em 1821). Este substituiu a abolição pelo subterfúgio do “ventre livre". Este arranjo permitiu às classes proprietárias de imediato, durante a guerra, a aparência "abolicionista" para utilizar uma parte dos escravos como soldados e, concluída, restaurar a escravidão (Cf. SALCEDO BASTARDO, p. 310).

Estes fatos assumem maior seriedade a partir de 1821 com a libertação da Venezuela na batalha de Carabobo. Não é casual observar as manobras obscuras do Congresso em Cúcuta em julho de 1821 e estando ele mesmo num dos centros do 
escravismo da Venezuela, em Valência, Bolívar escrevera: “O Congresso geral, autorizado por suas próprias leis, e mais ainda, pelas da natureza, pode decretar /já não pede a liberdade absoluta M.Z./ a liberdade absoluta de todos os colombianos ao ato de nascer em território da república... Por favor, V.E. levante esta solicitação de minha parte ao Congresso geral da Colômbia para que se digne concedê-la em recompensa pela batalha de Carabobo, vencida pelo exército libertador, cujo sangue correu apenas pela liberdade" (BOLÍVAR, 1982, p. 576). E se explica denotando a debilidade de sua própria posição como presidente naquele tempo: "Deste modo conciliam-se os direitos de propriedade, os direitos políticos e os direitos naturais" (Ibidem).

Não eram estes os únicos conflitos entre Bolívar e sua classe, está fora de qualquer dúvida que os representantes no Congresso eram representantes de sua própria classe, mais ainda, eram os mais progressistas e ilustrados representantes de sua classe. Sem poder analisar aqui em todos os detalhes, me permito indicar apenas mais dois aspectos, extremamente importantes porque referem-se diretamente à questão do poder: primeiro, os conflitos entre o legislativo e o executivo, que se desenvolvem desde o instante daquele ter sido criado por Bolívar, a princípios de 1819 em Angostura (ACTAS, 1969). "Escolhidos a mão”, os representantes no Congresso se converteram mais em entrave do que no apoio a Bolívar e seu exército libertador. Já em 1820 escreve: "Muito me tem incomodado as intrigas dos legisladores, e muito mais me convenço da impossibilidade que há entre nós de manter o equilíbrio. Será um milagre se salvamos sequer a pele desta revolução” (BOLÍVAR, 1982, p. 496). “Arar o mar" não é, desde visto dez anos antes, apenas uma expressão de misantropia e de decepção, é o resumo de toda a experiência vivida durante uma década com sua própria classe. Também em 1820 fala de sua "decisão de me salvar como possa entre estes inúteis, malvados, imbecis, ladrões, facciosos, ingratos e todos os cães do mundo" (Idem, 499). E dos representantes do Congresso diz: "as grandes autoridades de Angostura que, porque estão sobre o Orinoco, acreditam estar sobre o Tâmisa e que sendo da raça de Manaure, acreditam ser da de Pitt" (Idem, p. 500).

Segundo: os conflitos sobre a posição do exército e a constituição em geral. Bastante realisticamente Bolívar observa: "nossas coisas internas exigem que haja um grande exército para manter a autoridade do governo" (BOLÍVAR, 1982, p. 494). "Colômbia é governada pela espada dos que a defendem, e ao invés de ser um corpo 
social é um campo militar" (Idem, p. 551). Resumindo todos os problemas que vive, diz em 1820 sobre a Colômbia: "um Estado em que tudo vai contra meu sentimento". "Não posso ser cidadão da Colômbia, cujas leis não me conformo. Apresentei um projeto de Constituição que não foi aprovado. Aquele projeto era minha condição para ser cidadão da Colômbia. Não sendo adotado estou certo de que não haverá estabilidade política nem social; e destaco que aquele mesmo projeto não contém tudo o que eu penso que se requer para assegurar nossa existência" (Idem, p. 563).

Tudo supracitado permite chegar a uma conclusão: paralelamente a seus grandes trunfos militares começa a se abrir uma fissura cada vez mais profunda no seio da classe dirigente da revolução e em todo o campo revolucionário. Por um lado, está sendo formado um estrato social que surge principalmente entre a oficialidade do exército libertador e da alta burocracia, que está se enriquecendo e se convertendo, por sua posição política e administrativa, desde os primeiros êxitos duradouros da revolução num componente que freava a mesma e que servia de base para uma restauração socioeconômica. Por outro, o povo (nas palavras de Bolívar: "povo subalterno" (1982, p. 563) começava a ter suas esperanças de mudança frustradas, se não no essencial, mas perceptível em seu modo de viver. O próprio Bolívar, como membro de sua classe, o que ao fim e ao cabo seguia sendo, e em vista das dificuldades políticas que estava enfrentando, procure logo fugir frente a eles, e é isto - com a busca da glória - um motivo adicional que lhe força em direção ao Sul. Em setembro de 1821 escreve a respeito das acusações de ditador: "eu não vejo mais perigo que nas fronteiras. Só os godos são nossos inimigos; os outros são inimigos do general Bolívar e estes não se apresentam em batalha; se deve fugir deles para vencê-los" (Idem, p. 590).

IV

Porém, a expedição ao sul, a partir de junho de 1982, não se deve em primeiro lugar a motivos individuais e psicológicos, senão a fortes e justas razões de segurança da independência ainda não estabilizada. Ainda que não se exclua o aspecto de anexionismo (of. Guayaquil) e a exportação da revolução (Peru), parece que o aspecto

\footnotetext{
${ }^{7}$ No original lemos bajo pueblo, optamos traduzir por povo subalterno na falta de tradução melhor para a língua portuguesa (N.T.).
} 
da justa luta pela segurança prevalece. Com sua insistência em resolver este problema de segurança exterior, tanto da Colômbia fundada em 1819 quanto de Sul América na sua totalidade, Bolívar se revela Como um dos mais perspicazes revolucionários Americanos do seu tempo. A existência de fortes exércitos espanhóis no Peru e no Alto Peru, de fato, devia contribuir à instabilidade dos jovens Estados.

Mas, o remédio aplicado para curar a doença era, objetivamente e nas circunstâncias imperiosas, em vários aspectos quase tão nociva quanto a própria doença. Primeiro, a ausência de Bolívar e dos mais esclarecidos dos seus oficiais da Venezuela e Nova Granada permitia que lá se reforçasse rapidamente o "partido" antibolivariano. Este partido teria se formado ainda na sua presença, porém provavelmente não tão rápido. Segundo, a manutenção de um numeroso exército mobilizado e de ocupação deixou uma Colômbia esvaziada de homens e de meios financeiros, situação que contribui para acelerar os conflitos entre os interesses provincianos aparentes e os reais interesses estatais de longo alcance. Terceiro, a longa intromissão de Bolívar, Sucre e de outros militares nos assuntos nacionais de Equador, Peru e do Alto Peru que mais tarde se tornou Bolívia, devia aprofundar os receios nacionais. Mas, ao pesar os prós e contras de todos os problemas, Bolívar não poderia atuar razoavelmente de outro modo.

Se é verdade comprovada que cada revolução é válida desde que saiba se defender, Bolívar como representante mais ativo e perspicaz de um adequado princípio de defesa correspondeu a essa verdade, ainda que segundo o caráter e as possibilidades de essa revolução, aqui a definimos abreviadamente como burguesa. Ainda que o débil desenvolvimento das nações burguesas em Latino-América nesse tempo permita caracterizar a atuação de Bolívar como "internacionalista”, suas cartas provam que ele próprio a via principalmente sob o aspecto "nacional-grancolombiano". Seu programa federal, isto é, a ideia de uma grande federação entre Estados nacionais se nutre, em primeiro lugar, de motivações nacionais no atual sentido do termo. A parte dos conceitos que Bolívar tinha sobre o que ele denominava "povo subalterno" (BOLÍVAR, 1982, p. 563, 704), “os inimigos naturais de que se compõe nossa massa” (Idem, p. 695), os inimigos propriamente ditos que combatia tanto através de seu programa nacional quanto de seu ideário federativo de Estados nacionais não saíam do “povo subalterno”,

\footnotetext{
${ }^{8}$ Traduzido conforme a nota 5 (N.T.).
} 
mas da "elite" (Idem, p. 704). Assim diz em 1823, diante da tentativa prematura de mudar a constituição colombiana, ameaçando pela primeira vez usar suas faculdades discricionárias: "isso é o que querem os fofoqueiros: republiquetas e mais republiquetas para fazer revoluções e mais revoluções" (Idem, p. 713). "Nós seremos mais fortes quando estamos mais unidos, e esta união não nos virá nunca da satisfação pela independência e confiança sem limites; porque o dia em que nada temamos nesse dia começam os perigos da Colômbia; nesse dia ressoam as trombetas da guerra civil" (Idem, p. 718). Aproxima-se do cinismo quando fala de seu próprio país: "Quanto à Venezuela, sempre serei do ditado de que sua ruína será selada o dia que não reste um inimigo em seu território; tomara que Puerto Cabello fique sempre nas mãos dos inimigos" (Idem, p. 816). O que lhe inquieta é a "tranquilidade interior de América", como garantia da tranquilidade para cada Estado individual (1982a, p. 69): "Cada dia me convenço mais de que é necessário dar à nossa existência una base de garantia. Vejo a guerra civil e as desordens voarem por todas as partes, de um país a outro, meus deuses pátrios devorados pelo incêndio doméstico. Falo da Venezuela, meu querido país. Esta consideração me ocupa noite e dia; porque contemplo que a primeira desordem que nasça ali destrua para sempre até a esperança, porque ali o mal será radical e logo penetra até o sangue; volto, pois, ao meu primeiro projeto como único remédio: a federação" (Idem, p. 68). Ela deve ser estabelecida pelo "congresso americano que, pelo menos, deve servir-nos pelos dez ou doze anos de nossa primeira infância..." (Idem, p. 69, cf. ibidem, p. 88). Quer dizer, Bolívar pensa este Congresso anfictiônico como uma instituição permanente de vigilância e de ajuda mútua para garantir o desenvolvimento dos novos Estados. Sua orientação principal é contra as inatas tendências políticas de "repúblicas aristocráticas" ("anarquia”). Simultaneamente, não falta a orientação contra movimentos populares, em primeiro lugar os baseados nas raças ou cores. Assim diz no seu "Pensamento sobre o Congresso de Panamá” (1820): “9º) A América não temeria mais ao tremendo monstruoso que devorou a ilha de Santo Domingo; tampouco temeria a preponderância numérica dos primitivos habitantes" (LECUNA, 1983, p.136). Porém, é claro que este tema parece, em Bolívar, absolutamente secundário. Situação contrária vale enquanto ao aspecto exterior: o Congresso deve formar uma liga dos Estados contra todo esforço de

\footnotetext{
${ }^{9}$ No original lemos alto pueblo, optamos traduzir por elite na falta de tradução melhor para a língua portuguesa (N.T.).
} 
menosprezar sua posição independente. Esta era então uma orientação principal. Não podemos nos ocupar da ideia de federação dos Estados hispano-americanos como estava desenvolvendo Bolívar e na totalidade de seus aspectos, deve destacar-se que Bolívar estava longe de construir um castelo no ar. Dezenas de referências nas suas cartas permitem ver com quanta cautela e perspicácia a preparava, especialmente seus aspectos exteriores, em primeiro lugar, com vistas ao predomínio britânico (BOLÍVAR, 1982a, p. 116, 129, 160, 169-170, 351) e a rivalidade dos Estados Unidos. Bolívar não tinha nenhuma ilusão e observava tanto a atitude hostil das grandes potências do seu tempo diante da plena independência e soberania como também a incapacidade dos elementos internos realmente nacionalistas e burguês-progressistas. Não é menos verdadeiro que Bolívar, tanto por preconceito frente aos movimentos do "povo subalterno" quanto por razões justificadas sob as condições sociais de seu tempo, nunca pensou seriamente em uma guerra libertadora, conduzida por ele em Cuba e Porto Rico (Idem, p.59, 137). Pensava sempre na experiência de Haiti como na tentativa de [Manuel] Piar $^{10}$ ou na participação tardia de [José Prudencio] Padilla ${ }^{11}$ na conspiração de setembro (1828) (BOLÍVAR, 1982 b, p. 116; 48, 64, 116) ${ }^{12}$. Não é somente por ter sido filho da sua classe, que de fato era; porém para criar a nação e estabilizar o Estado não quis arriscar conflitos que conduzissem a uma guerra de raças.

Muitas vezes Bolívar foi acusado de ditador por ser ambicioso, por tendências inatas à ditadura. Nada mais equivocado do que isso. O problema da ditadura, em termos científicos, é um risco de qualquer revolução. Muito pior ainda durante a revolução de independência, que por definição é uma revolução cujas condições nem todos os pressupostos econômicos e sociais existiam para um desenvolvimento

\footnotetext{
${ }^{10} \mathrm{O}$ autor refere-se ao general venezuelano Manuel Piar. Sobre sua participação nas guerras de independência ver Ríos, Alícia. (1993). La época de la independencia en la narrativa venezolana de los ochenta. Hispamérica, 49-54 (N.T.).

${ }^{11}$ Foi almirante e militar colombiano de ascendência parda, chegando a ser Almirante da República, e com enorme popularidade sendo Senador da Gran Colômbia em 1822. Foi condenado por conspiração e traição na "Conspiração Setembrina" e executado por ordem de Bolívar em 1822 (N.T.).

${ }^{12} \mathrm{Em} 25$ de novembro de 1828 fora armado um intento de assinar Simón Bolívar sob o argumento de sua postura autoritária e ditatorial, justamente uma das questões centrais que o artigo em questão busca rebater desde uma análise de classe da luta de independência (N.T.).
} 
"normal" do capitalismo e da sociedade burguesa, ou seja, onde o político substitui em grande parte as condições econômico-sociais existentes. Assim, a debilidade dos laços nacionais devia ser substituída - ou reforçada - por vínculos de tipo político ou ideológico. Nisso reside o grande papel da "ilusão heroica" de Bolívar durante a revolução até Ayacucho; depois, realmente sua importância teria sido ainda maior, pelas destruições e devastação das guerras e, com isso, das condições para um desenvolvimento nacional mais rápido. Porém, não sentia mais seus efeitos (BOLÍVAR, 1982a, p.430-431). Aí reside também o papel do exército e sua unidade como fundamento para a construção de Estados nacionais, e o papel do próprio Bolívar. Foi constatado que Bolívar não era dogmaticamente liberal ou conservador; ainda que se inscrever em uma ampla compreensão do liberalismo, era fundamentalmente um revolucionário que durante a revolução quis fazê-la triunfar, e depois de seu triunfo se esforçou por conservá-la, buscando todos os meios para lográ-la. Por isso, suas expressões amarguradas contra os representantes do dogmatismo liberalóide, que sacrificava a revolução aos princípios vazios de seu conteúdo libertador. Ou seja, contra um liberalismo que aos seus olhos se convertia em ideologia política de uma parte da classe latifundiária. Bolívar, como se pode observar em todas suas atividades revolucionárias, compreendeu profundamente o que Marx conceituou mais tarde como uma lei geral da revolução, tanto a burguesa quanto a socialista: "Cada conjuntura provisória de Estado depois de uma revolução requer de uma ditadura, e necessariamente, de uma enérgica" (MARX, 1961, p. 402). Objetivamente Bolívar atuou nesse sentido, embora sem sucesso global e duradouro, porque na medida em que triunfou a independência triunfaram, majoritariamente, os elementos regionalistas e provinciais que nada queriam saber sobre metas nacionais ou continentais e que, no nível político se interessavam por seu governinho, sua republiqueta e sua independência. Essa atitude colocou em perigo a estabilidade política e social, ameaçando com a ruptura do "sistema social" entre a "elite e povo subalterno" (BOLÍVAR, 1982a, p. 705), conforme notificou Bolívar em 1822. Por isso começou a dizer: "não servirei na presidência senão pelo exercício das faculdades ilimitadas concedidas pelo congresso; porque estou intimamente convencido de que a república da Colômbia não se governará com prosperidade e ordem salvo pelo poder absoluto... Para colômbia se requer um exército de ocupação que a mantenha em liberdade" (Ibidem), porque - extremamente importante -: “ a primeira qualidade das coisas é a 
existência e as demais são secundárias" (Idem, p. 708). Por esse motivo, transforma-se de inimigo da constituição que considerava insuficiente em seu defensor mais enérgico quando tentavam debilitá-la: "reitero... minha primeira promessa de antes morrer, de espada na mão, encabeçando o exercício da Colômbia do que permitir que se deprecie o pacto de união que apresentou uma nação ao mundo, formada por Venezuela e Nova Granada. A constituição da Colômbia é sagrada por dez anos: não se violará impunemente enquanto corra sangue pelas minhas veias e estejam sob minhas ordens os libertadores" (Idem, p. 710). Constatando nessas controvérsias o fortalecimento das tendências opostas e que não poderia se apoiar na maioria de sua própria classe ou do "povo subalterno", foi necessário o papel de sua própria personalidade para a conservação dos logros da revolução, dizendo: "Cada dia se confirma a ideia de que Colômbia se conservará unida enquanto os libertadores se conservem a mim unidos, porém depois haverá guerras civis” (Idem, p. 943). Não se pode encontrar nos seus contemporâneos melhor definição do seu papel individual na dura e difícil luta pela estabilidade vital dos jovens Estados independentes. Essa observação tem importância também para determinar o papel do exército naquele período. Estou em pleno acordo com Manfred Kossok, na sua exigência para distinguir entre "ditadura de primeira hora" e "ditadura pretoriana" nas mãos das classes exploradoras para conservar um sistema caduco. De fato, não há nenhuma razão para equiparar as ditaduras revolucionárias às restaurativas ou reacionárias. Isto resulta claramente do princípio de Bolívar separar o poder civil do poder militar; sendo presidente desde 1819 sempre se considerava "Presidente titular" (1982a, p. 42), porém nunca renunciou ao comando do exército enquanto única garantia da ordem revolucionária, e considerava o "poder absoluto" como a constante possibilidade e faculdade de exercer a intervenção militar a favor desta ordem. Prova disso foi sua atitude diante dos acontecimentos de 1836 em Venezuela, embora naquele tempo já fosse tarde para salvar a união da Grande Colômbia como núcleo de unidade americana. Por isso, com esses fatos começava a decadência e derrubada da ordem bolivariana, iniciava-se o último ato da sua tragédia como revolucionário e como homem de Estado. É uma tragédia real e verdadeira, porque Bolívar não capitula nem nos últimos meses de vida, senão que continua lutando para defender sua obra.

A sorte de Bolívar tinha que ser necessariamente trágica. Sua grande ilusão heroica de criar, mediante a libertação das antigas colônias espanholas da América, 
uma família de nações prósperas e florescentes se revelava após três lustros de lutas, realmente, heróicas e de seus próprios triunfos, pelo menos em grande parte como uma ilusão, porém, necessária. Marx observou-o na ótica colorida, em parte pelas tradições liberal-democrática, em parte, apoiando-se em fontes impuras e, como terceiro ingrediente, na luta contra o incipiente culto conservador-oligárquico à Bolívar. Confundiu a tragedia bolivariana com a farsa de [Charles-Louis] Napoleão III $^{13}$ ou a tragicomédia de [Faustín Elié-] Souloque ${ }^{14}$ e combatendo a través de Bolívar o culto ao terceiro Napoleão (MARX, 1961a, p. 116).

As comparações com Napoleão III e, especialmente, com Soulouque parecem chocantes, em todo caso são equivocadas, porém, há na verdade só um nível de comparação possível, que é a hipertrofia do político sobre o econômico que parece igualar os três casos. Porém, no tocante ao problema do bonapartismo existem diferenças fundamentais que proíbem a comparação. $\mathrm{O}$ aspecto mais importante que a proíbe é o fato de Bolívar ser um representante de uma verdadeira revolução, ainda que de tipo antiquado ou "inferior", na qual a hipertrofia do político é algo normal. Enquanto que nos outros casos as personalidades referidas não atuam como líderes revolucionários de um processo revolucionário, senão que ao contrário, contrarrevolucionário (Napoleão III) ou rural-arcaico (Soulouque). o próprio Marx em carta (MARX, 1970, p. 280) explica através do artigo sobre Bolívar buscou uma comparação entre Bolívar e Napoleão I, especialmente, sobre o ponto de vista comparativo militar. Porém com a consequência de omitir a comparação históricorevolucionária, o que poderia ter dado um resultado diferente. Porém, as fontes desse momento e o instrumento marxista, elaborado no final dos anos cinquenta do século passado, não eram suficiente. Nos anos setenta, pode afirmar-se, um estudo sobre Bolívar teria resultados muito diferentes, então Marx tendo em mãos estudos comparativos com outras regiões e países atrasados. Por isso, e para impedir o uso do artigo de Marx sobre Bolívar na luta contra o marxismo-leninismo, como o faz um número considerável de historiadores e jornalistas burgueses da América Latina,

\footnotetext{
${ }^{13}$ Sobrinho de Napoleão Bonaparte foi responsável pelo primeiro tipo de golpe de Estado moderno ocorrido em 1851, numa forma de aliança civil-militar com intuito de barrar qualquer avanço do movimento operário-popular, mas também pela impossibilidade de imposição de um projeto próprio da grande burguesia na França durante a Revolução de 1848 ou Primavera dos Povos como disse Eric Hobsbawn (N.T.).

${ }_{14}$ Autoproclamado Faustino I do Haiti, ainda que tivesse certa intenção de extirpar os remanescentes brancos e mulatos de postos do poder no conturbado e longo processo de construção nacional haitiana, tendeu a reproduzir vícios aristocráticos napoleônicos (N.T.).
} 
fazem falta estudos aprofundados de historiadores marxistas-leninistas tanto sobre Bolívar quanto da história da revolução da independência.

Apesar de Bolívar lutar por metas inalcançáveis em seu tempo, garantiu com sua luta, pelo menos, a conquista da independência política, estas metas têm ainda hoje plena vigência. É claro que nem a classe de a qual Bolívar pertenceu e nem as atuais burguesias dos países latino-americanos têm capacidade ou disposição de responsabilizar-se com ou pelo legado de Bolívar. Assim, este legado pertence aos revolucionários de hoje. Pode-se afirmar que a figura de Bolívar e seu programa vivem plenamente na consciência dos revolucionários e dos povos latino-americanos. Do nosso trabalho, os historiadores marxistas-leninistas, depende muito dos estudos que estamos fazendo e os que faremos, do conhecimento cabal, a análise diferenciada, a mensagem revolucionária nas suas obras, para que possam enriquecer o instrumental de luta ideológica e política atual.

Resumindo, quais são os pontos mais essenciais do programa e da atuação histórica de Bolívar?

- sua constância e sua perseverança revolucionárias, lutando por seus objetivos até o esgotamento de suas capacidades;

- sua compreensão da necessidade de união de todos os revolucionários para lograr o triunfo da revolução;

- sua disposição de renunciar, pela questão da unidade e pertencendo a uma classe privilegiada, ao menos a uma parte destes privilégios;

- sua compreensão de que sem unidade política, armada e ideologicamente protegida, sem o problema do poder resolvido, a revolução não poderá sobreviver;

- sua orientação para a independência plena e soberana, partindo do cálculo frio e cuidadoso tanto próprios interesses como o dos outros países, tendo uma ideia muito clara da correlação internacional de forças;

- suas advertências constantes sobre o perigo do expansionismo dos Estados Unidos e o peso comercial e económico crescente da Grã-Bretanha. Nesse sentido, foi um precursor do anti-imperialismo;

- seu programa e seu ideal de solidariedade internacional latino-americana com conteúdo revolucionário e progressista, ligados à ideia de conquistar um novo equilíbrio do universo mediante o aumento do peso dos países latino-americanos na balança internacional. 


\section{Referências}

ACOSTA SAIGNES, Miguel. Bolívar: acción y utopía del hombre de las dificultades. La Habana: Casa de las Américas, 1977.

BOLÍVAR, Simón. Obras Completas, Tomo 1. Caracas: Librería Piñango, 1982.

BOLÍVAR, Simón. Obras Completas, Tomo 2. Caracas: Librería Piñango, 1982a.

BOLÍVAR, Simón. Obras Completas, Tomo 3. Caracas: Librería Piñango, $1982 b$.

ACTAS. Actas del Congreso de Angostura. Caracas: Instituto de Derecho Público, 1969.

LECINA, Vicente (ed.). Cartas del Libertador, t. I, 1799-1817. Caracas: 1929.

LECUNA, Vicente (org.). Proclamas y discursos del Libertador, 1811-1830, t. 13. Los Teques: Biblioteca de Autores e Temas Mirandinos, 1983.

MAGALlANES, Manuel Vicente. História Política de Venezuela, tomo I. Caracas: Librería Piñango, 1982.

MARX, Karl. "Die Krisis und die Kontrerevolution (1848)" in Marx-Engels-Werke Bd.5. Berlin: 1961. [tradução para o português em MARX, Karl. A burguesia e a contrarrevolução. São Paulo: Ensaio, 1993].

MARX, Karl. "Bolívar y Ponte”, in: Marx-Engels-Werke Bd.10. Berlin: 1961a. [tradução para o português em MARX, Karl. Bolívar y Ponte. São Paulo: Martins Fontes, 2008]. MARX, Karl."Espartero" in Marx-Engels-Werke Bd.10. Berlin: 1961b.

MARX, Karl. “K. Marx a F. Engels, fevereiro 14, 1858”, in: Marx-Engels-Werke Bd.29. Berlim: 1970.

NUCETE-SARDI, José. “Conjuración de Caracas en 1808” in Boletín de la Academia Nacional de la Historia, tomo LII, nº 207, 1969.

SALCEDO BASTARDO, José Luís. Bolivar: un continente y un destino. Caracas: 1972. 